\title{
Implementasi Metode Selection Sort Untuk Menentukan Barang Yang Harus Di Stok Ulang Dalam Sistem Informasi Penjualan
}

\author{
Zaima Faiza Hakim \\ Program Studi S2 Pendidikan Teknologi dan Kejuruan, Universitas Negeri Surabaya \\ zaimahakim16070895036@mhs.unesa.ac.id
}

\begin{abstract}
Abstrak-Teknologi pada zaman sekarang semakin canggih dan hampir semua dalam kehidupan sehari-hari pasti tidak akan lumput dengan adanya teknologi. Teknologi yang semakin canggih dapat mempermudah semua orang dalam melakukan berbagai aktivitas. Pada proses jual beli manual sering kali lupa mencatat stok barang, barang masuk dan barang keluar terkadang tidak sama dengan catatan. Kemudian pada proses jual beli manual terkadang ada orang mencari suatu barang ternyata barang tersebut sudah habis dan penjual lupa untuk merestok ulang barang. Hal-hal demikian yang dapat dipermudah untuk mengingatkan barang apa saja yang perlu distok ulang. Dengan adanya sistem informasi berbasis web namun dapat dijalankan secara offline dapat membantu user dalam proses jual beli. Dalam sistem penjualan ini terdapat pengolahan data barang, data suplier, data customer, data penjualan dan data pembelian. Pada data barang juga akan memberi tahukan kepada user apabila stok barang tinggal sedikit agar user dapat mempersiapkan barang apa saja yang harus di beli kembali dari suplier. Terdapat laporan dalam bentuk .pdf yang nantinya dapat dicetak. Metode $t$ yang digunakan yaitu ascending atau mengurutkan dari nilai terkecil ke terbesar dari stok barang. Pada sistem ini data barang dapat urut agar mempemudah user untuk mengecek barang yang perlu distok kembali. Penerapan metode Selection Sort pada sistem informasi penjualan menggunakan PHP dengan database PostgreSQL. Output yang dihasilkan dari sistem informasi penjualan ini adalah laporan data barang yang telah terurut dari stok paling sedikit dan stok paling banyak.
\end{abstract}

Kata Kunci-selection sort, Sistem Penjualan

\section{Pendahuluan}

Dokumen Teknologi pada zaman sekarang semakin canggih dan hampir semua dalam kehidupan sehari-hari pasti tidak akan lumput dengan adanya teknologi. Teknologi yang semakin canggih dapat mempermudah semua orang dalam melakukan berbagai aktivitas.

Pada proses jual beli manual sering kali lupa mencatat stok barang, barang masuk dan barang keluar terkadang tidak sama dengan catatan. Kemudian pada proses jual beli manual terkadang ada orang mencari suatu barang ternyata barang tersebut sudah habis dan penjual lupa untuk merestok ulang barang. Hal-hal demikian yang dapat dipermudah untuk mengingatkan barang apa saja yang perlu distok ulang.

Dengan adanya sistem informasi berbasis web namun dapat dijalankan secara offline dapat membantu user dalam proses jual beli. Dalam sistem penjualan ini terdapat pengolahan data barang, data suplier, data customer, data penjualan dan data pembelian. Pada data barang juga akan memberi tahukan kepada user apabila stok barang tinggal sedikit agar user dapat mempersiapkan barang apa saja yang harus di beli kembali dari suplier. Terdapat laporan dalam bentuk .pdf yang nantinya dapat dicetak

Sistem penjualan dan pembelian ini dibuat dengan PHP yang nantinya berupa website namun offline yang hanya dapat dijalankan pada PC yang terdapat sistem tersebut. Dibuat dengan PHP untuk mempermudah user. User dengan menggunakan sistem operasi apapun baik linux ataupun windows dapat menggunakan sistem ini. Namun dalam uji coba produk penulis menggunakan sistem operasi windows.

Berdasarkan masalah di atas, penulis akan merancang dan membuat sistem informasi yang diharapkan dapat mengatasi masalah tersebut dengan judul : "Implementasi Metode Selection Sort untuk Menentukan Barang yang Harus Di Stok Ulang Dalam Sistem Informasi Penjualan.”.

\section{KAJIAN PUSTAKA}

\section{A. Sistem Informasi}

Williams dan Sawyer [4] menyatakan SIM (Sistem Informasi Manajemen) adalah sistem informasi berbasis komputer yang menggunakan data yang ada pada TPS sebagai input pada program - program yang menghasilkan laporan rutin sebagai output. Sistem Informasi merupakan sebuah sistem yang membantu orang/perusahaan (user) untuk menggolah, menyajikan serta memanagemen suatu informasi atau data - data.

Contoh dari sistem informasi misalnya, sistem toko buku. Sitem informasi toko buku biasanya menyajikan informasi tentang stok - stok buku, transaksi penjualan dari toko tersebut, laporan - laporan. Seorang manajer pasti membutuhkan data stok buku yang mana apabila buku tersebut habis maka manajer harus mengadakan kembali buku tersebut.

Sistem Informasi penjualan dan pembelian merupakan suatu sistem untuk mengelola data - data dalam melakukan transaksi penjualan dan pembelian. Sistem informasi ini dapat mengelola data barang, data suplier, data customer, data penjualan dan data pembelian.

\section{B. Sistem Informasi Penjualan}

Sistem Informasi penjualan merupakan suatu sistem informasi untuk mengelola data - data dalam melakukan transaksi penjualan. Sistem informasi ini dapat mengelola data 
pembelian.

Data barang merupakan data - data yang berkaitan dengan spesifikasi dari barang - barang tersebut baik dari segi harga jual maupun harga beli. Pada data barang sistem ini juga memberi informasi kepada user apabila stok barang tinggal sedikit dengan munculnya warna yang berbeda pada data barang, hal ini agar user dapat memperkirakan barang apa saja yang harus di beli kembali dari suplier.

Data suplier merupakan data - data untuk menyimpan dan menegelola data - data suplier yang berkaitan dengan spesifikasi dari suplier misal nama suplier, alamat, no telepon, dll. Sama dengan halnya data suplier, data customer juga mengelola data ataupun informasi terkait dengan customer misal nama customer, alamat, dan no telepon.

Data penjualan merupakan pengelolaan data penjualan. Barang - barang yang di beli oleh para customer akan di kelola dalam data penjualan. Data - data yang berkaitan dengan data penjualan di sini adalah data barang dan data customer. Apabila barang yang sudah di beli oleh customer, data barang akan mengupdate data barang tersebut dan otomatis stok pada data barang berkurang sesuai dengan jumlah yang dibeli oleh customer.

Data pembelian merupakan pengelolaan data pembelian dari suplier. Data - data yang berkaitan dengan data pembelian adalah data barang dan data suplier. Barang barang yang dibeli dari suplier melalui data pembelian ini nanti akan otomatis bertambah dalam stok barang.

Pada sistem informasi ini dapat mencetak nota penjualan. Jadi para customer dapat mengetahui barang apa saja yang telah dibeli. Selain nota penjualan juga terdapat laporan stok, laporan barang habis, laporan pembelian, dan laporan penjualan yang dapat dilihat sesuai dengan periode tanggal. Laporan - laporan tersebut berupa format .pdf dan dapat dicetak.

Namun kekurangan dari sistem penjualan yang dibuat oleh penulis kurang adanya perhitungan kembalian, jadi apabila customer membayar dengan uang yang lebih dari total belanja user masih harus menggunakan cara manual untuk memberi kembalian kepada customer. Kemudian kekurangan yang lainnya adalah tidak adanya diskon dan return barang ke suplier.

\section{PHP (Personal Home Page)}

PHP adalah sebuah piranti yang dapat dipakai untuk membuat aplikasi berbasis website. Aplikasi web adalah aplikasi yang dijalankan melalui browser [8]. PHP merupakan salah satu bahasa scripting yang banyak digunakan oleh para web development. PHP banyak digunakan para programmer untuk membangun web. PHP yang bersifat server side scripting maka dalam pembuatannya membutuhkan web server, misal dapat menggunakan web server xampp, wampp, dan lain - lain.

\section{JavaScript}

Betha Sidik [9] menyatakan JavaScript adalah bahasa yang digunakan agar dokumen HTML yang ditampilkan dalam browser menjadi lebih interaktif, tidak sekedar indah saja. JavaScript merupakan program yang berbentuk script yang dijalankan oleh interpreter yang telah berada pada web browser. Jadi apabila web browser yang telah memiliki interpreter JavaSript maka web browser yang akan menjalankan program JavaScript tersebut. JavaScript menggunakan tag yang di awali dengan $<$ script...... $>$ dan di akhiri dengan $</$ script $>$ tag ini dapat di sisipkan di HTML sehingga akan menampilkan dokumen HTML pada web browser.

Salah satu contoh penggunaan JavaScript pada sistem penjualan dan pembelian adalah menggunakan fungsi atau method dari document getElementByid ('idobjek') yang akan menghasilkan sebuah variabel objek. Berdasarkan variabel objek tersebut mendapatkan properti dari objek tersebut. Misalnya dengan contoh source code pada saat login. Berikut adalah potongan source code untuk membuat textbox untuk tampilan login.

$$
\begin{array}{cr}
<\text { input type="text" name="vkdlogin" id="vkdlogin" } \\
\text { style="width:100px; } 20 \mathrm{px} "
\end{array}
$$$$
\text { onkeydown="PindahFocus(event,'vkdpassword',")"/> }
$$

Berikut adalah potongan source code JavaScript getElementByid('idobjek')

var login=document.getElementById("vkdlogin").value;

Pada potongan program di atas dapat dilihat bahwa pada saat membuat tampilan meggunakan id vkdlogin dan akan menyimpan hasil dari document.getElementById("vkdlogin") ke dalam variabel login.

\section{E. PostgreSQL}

PostgreSQL merupakan sebuah Object-Relational Database Management System (ORDBMS) yang open source. PostgreSQL merupakan DBMS yang dapat menjalankan bahasa SQL dan mempunyai kelebihan fitur - fitur modern seperti, Complex Queries, Foreign Keys, Triggers, View, Transactional Integrity, Multiversion Concurrency Control.

Untuk memperoleh postgresql dapat mendownload pada alamat berikut http://www.postgresql.org/download/ . Pada saat anda mengintall postgresql anda akan diminta untuk mengisi password yang nantinya digunakan seterusnya pada saat menggunakan postgresql.

\section{F. PostgreSQL}

Menurut Abidin [2], metode Selection Sort merupakan perbaikan dari metode bubble sort dengan mengurangi jumlah perbandingan. Selection Sort merupakan metode pengurutan dengan mencari nilai data terkecil dimulai dari data diposisi 0 hingga diposisi $\mathrm{N}-1$. Jika terdapat $\mathrm{N}$ data dan data terkoleksi dari urutan 0 sampai dengan N-1 maka algoritma pengurutan dengan metode Selection Sort adalah sebagai berikut : $\mathrm{N}-1$

1) Cari data terkecil dalam interval $\mathrm{j}=0$ sampai dengan $\mathrm{j}=$ 
2) Jika pada posisi pos ditemukan data yang terkecil, tukarkan data diposisi pos dengan data di posisi i jika $\mathrm{k}$.

3) Ulangi langkah 1 dan 2 dengan $\mathrm{j}=\mathrm{j}+\mathrm{i}$ sampai dengan $\mathrm{j}=$ $\mathrm{N}-1$, dan seterusnya sampai $\mathrm{j}=\mathrm{N}-1$.

Bila diketahui data awal berupa: 445512429418667 , maka langkah perlangkah pengurutan dengan metode Selection Sort ditunjukkan pada Tabel 1.

TABEL I

TYPE LANGKAH PENGURUTAN DENGAN MENGGUNAKAN METODE SELECTION SORT

\begin{tabular}{|c|c|c|c|c|c|c|c|c|}
\hline 44 & 55 & 12 & 42 & 94 & 18 & 06 & 67 & Data Awal \\
\hline 06 & 55 & 12 & 42 & 94 & 18 & 44 & 67 & Tukarkan data ke 1 dengan data ke 7 \\
\hline 06 & 12 & 55 & 42 & 94 & 18 & 44 & 67 & Tukarkan data ke 2 dengan data ke 3 \\
\hline 06 & 12 & 18 & 42 & 94 & 55 & 44 & 67 & Tukarkan data ke 3 dengan data ke 6 \\
\hline 06 & 12 & 18 & 42 & 94 & 55 & 44 & 67 & Data ke 4 tichak ditukarkan \\
\hline 06 & 12 & 18 & 42 & 44 & 55 & 94 & 67 & Data ke 5 dinukarkan dengan data ke 7 \\
\hline 06 & 12 & 18 & 42 & 44 & 55 & 94 & 67 & Data ke 6 tidink ditukarkan \\
\hline 06 & 12 & 18 & 42 & 44 & 55 & 67 & 94 & Data ke 7 dinukarikan dengan data ke 8 \\
\hline 06 & 12 & 18 & 42 & 44 & 55 & 67 & 94 & Data setelah terurut \\
\hline
\end{tabular}

Menurut Rahayuningsih [1] Selection Sort dalam mengurutkan data lebih cepat dibandingkan dengan buble sort. Jadi pada sistem informasi penjualan untuk menentukan stok barang yang akan habis lebih baik menggunakan selection dari pada buble sort. Menurut Tjaru [6] Selection Sort kompleksitasnya relatif kecil dan algoritma Selection Sort tidak stabil.

\section{METODE}

Jenis penelitian yang digunakan dalam penelitian. Pada bab ini, dibahas metodologi penelitian, tahapan penelitian, subjek penelitian, desain teknologi yang digunakan. Tahapan penelitian pengembangan perangkat lunak mengacu pada System Development Life Cycle metode waterfall yang meliputi:

\section{A. Analisis kebutuhan (Requirement)}

Perangkat lunak harus sesuai dengan kebutuhan user dan proses bisnis yang telah berjalan. Kebutuhan user terkait penelitian ini antara lain: data barang, sistem penjualan, sistem pembelian, laporan data stok yang perlu di stok ulang.

\section{B. Desain/Perancangan (Design)}

Pada tahap ini dilakukan desain sistem berdasarkan rekayasa kebutuhan yang sudah dilakukan pada tahapan requirement. Desain sistem meliputi: desain proses, desain database, desain user interface, dan desain teknologi yang digunakan.
1) Desain proses

Perancangan proses manajemen skripsi ini akan diperlihatkan dengan menggunakan data flow diagram (DFD) diperlihatkan pada Gbr 1. Untuk desain data diperlihatkan dengan menggunakan ERD seperti pada Gbr 2.

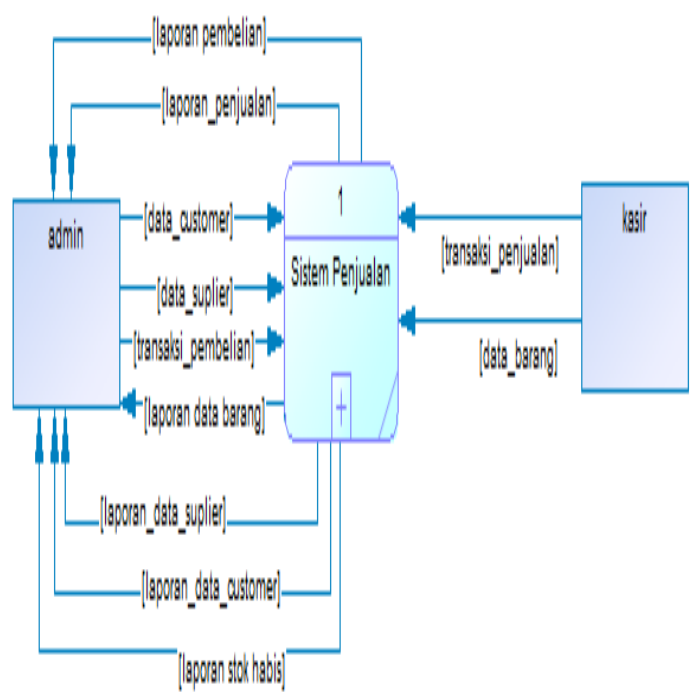

Gbr. 1 DFD Sistem Penjualan

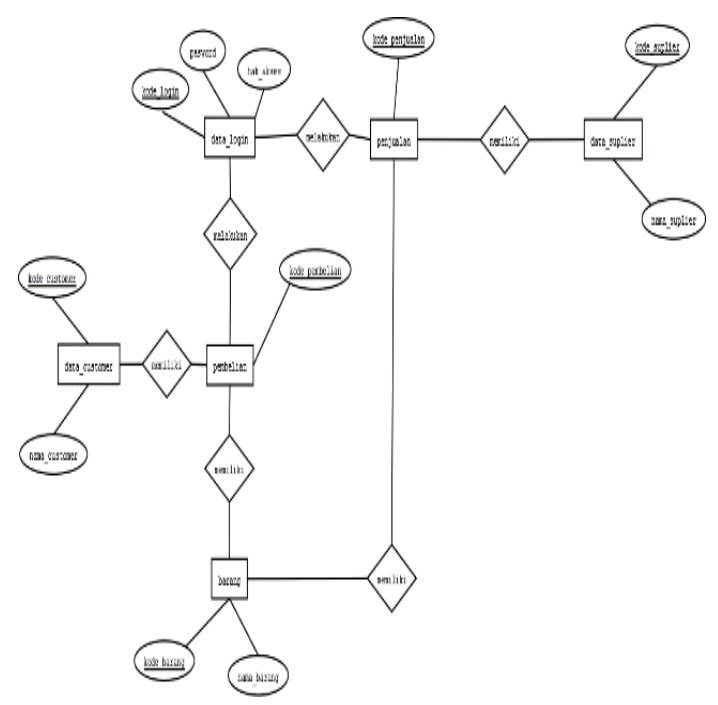

Gbr. 2 DFD Sistem Penjualan 


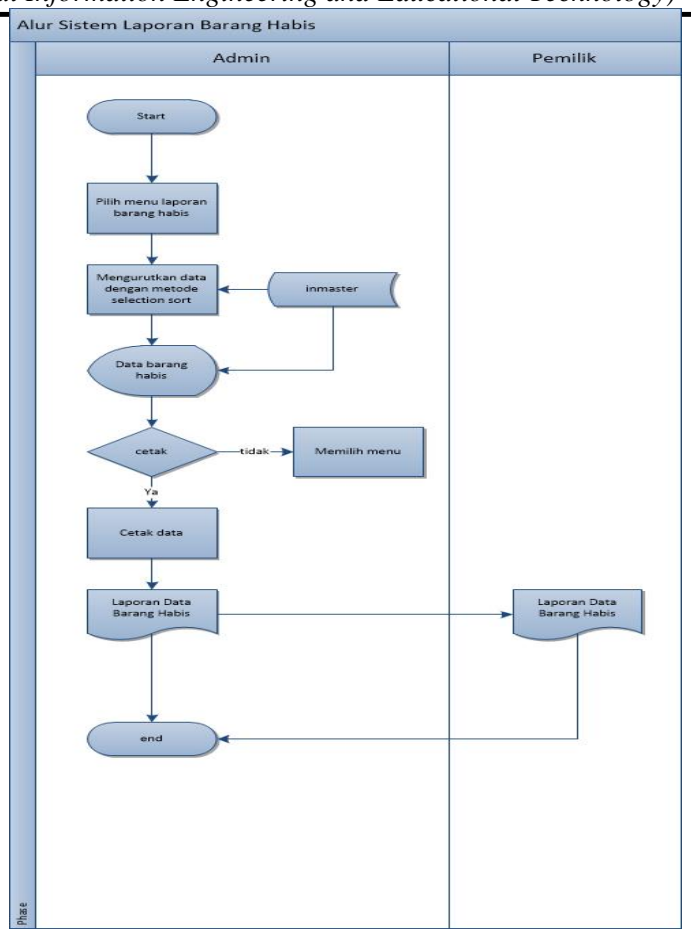

Gbr. 3 Flowchart Sistem Laporan Barang Habis

\section{Implementasi (Implementation)}

Pada tahap ini dilakukan translasi dari rekayasa kebutuhan dan desain sistem menjadi perangka lunak, dalam bentuk pemrograman (software development). Pada tahapan ini, perangkat lunak dipecah menjadi beberapa modul antara lain: master barang, master customer, master suplier, master penjualan, master pembelian.

\section{Verifikasi (Verification)}

Pada tahap ini dilakukan pengujian perangkat lunak sebelum benar-benar digunakan pada proses bisnis yang sebenarnya. Pengujian dilakukan dengan mensimulasikan baik data maupun proses seperti yang sebenarnya. Jika masih terdapat error maupun bug dilakukan proses perbaikan. Dari tahapan ini diharapkan perangkat lunak terbebas dari error dan telah sesuai dengan kebutuhan user.

\section{E. Pemeliharaan (Maintenance)}

Perangkat lunak yang sudah digunakan, masih perlu dilakukan perawatan karena kesalahan (bug) selama perangkat lunak digunakan. Perawatan dilakukan agar perangkat lunak terbebas dari kesalahan dan dapat menyesuaikan dengan kebutuhan-kebutuhan baru.

\section{HASIL UJI COBA DAN PEMBAHASAN}

Bab ini akan memaparkan hasil implementasi dari perancangan sistem dan metode rekayasa yang telah dijelaskan pada bab sebelumnya. Berikut ini tampilantampilan hasil implementasi dari sistem informasi penjualan.

\section{A. Halaman Awal}

Halaman awal merupakan halaman pada saat membuka sistem informasi penjualan dengan web browser. Untuk admin username diisi dengan admin dan password diisi dengan admin kemudian klik button Login seperti pada Gbr 4.

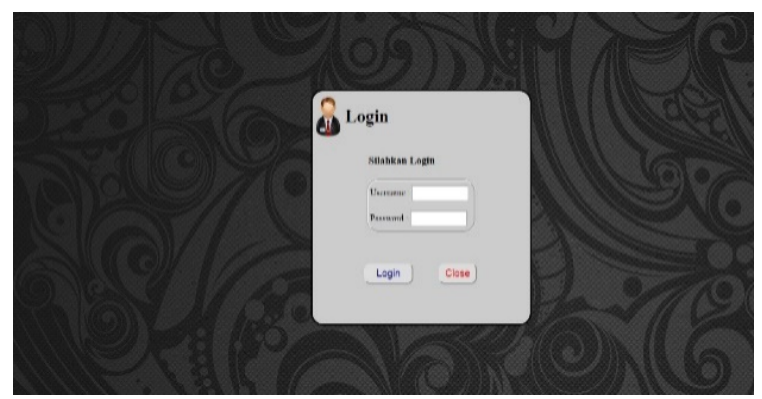

Gbr. 4 Tampilan Halaman Awal Sistem Informasi Penjualan

\section{B. Halaman Awal}

Terdapat tiga menu untuk admin yaitu menu master, transaksi dan laporan. Untuk menu master dibagi kembali menjadi menu master customer, master barang, master suplier, data customer, data barang, dan data suplier. Untuk menu transaksi dibagi kembali menjadi menu transaksi penjualan dan transaksi pembelian. Pada menu laporan terdapat beberapa menu pula yaitu menu laporan stok, laporan barang habis, laporan penjualan, dan laporan pembelian seperti pada Gbr 5.

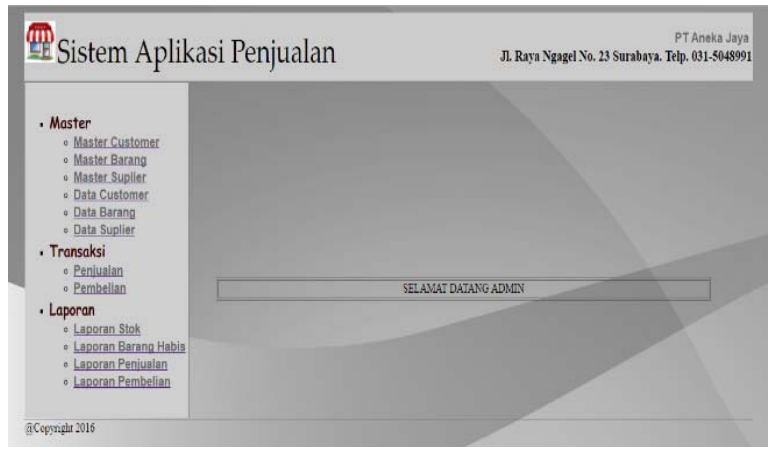

Gbr. 5 Tampilan Halaman Menu Admin Sistem Informasi Penjualan

\section{Halaman Master Customer}

Halaman master customer berisi tentang data - data yang dibutuhkan untuk data customer yaitu kode customer, nama customer, alamat dan no.telp. Pada master customer level admin dapat menyimpan, menghapus, mengkoreksi dan juga mencari data customer seperti pada Gbr 6 . 


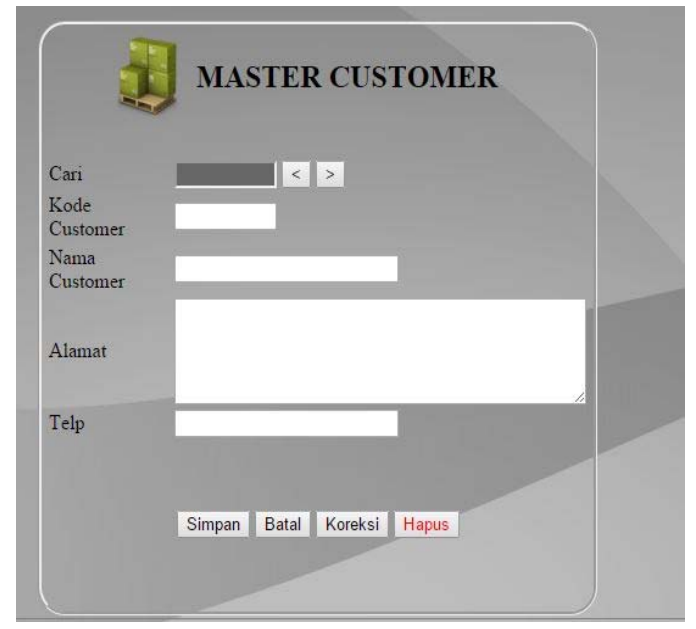

Gbr. 6 Tampilan Halaman Menu Master Customer Sistem Informasi Penjualan

\section{Halaman Master Barang}

Pada master barang, admin dapat melakukan kegiatan menyimpan, mengkoreksi, menghapus dan juga mencari data barang. Master barang disini menyimpan data - data yang diperlukan untuk master barang yaitu kode item, nama barang, satuan, stok, harga beli, dan harga jual seperti pada Gbr 7 .

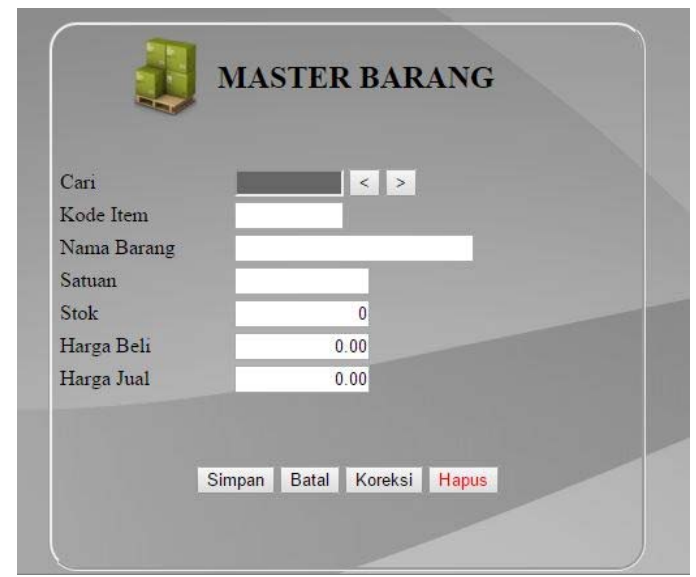

Gbr. 6 Tampilan Halaman Menu Master Barang Sistem Informasi Penjualan

\section{E. Halaman Master Suplier}

Master suplier disini menyimpan data - data yang diperlukan untuk master suplier yaitu kode suplier, nama suplier, alamat, no.telp, dan contact person. Pada master suplier admin dapat melakukan kegiatan menyimpan, mengkoreksi, menghapus dan juga mencari data suplier seperti pada Gbr 8.

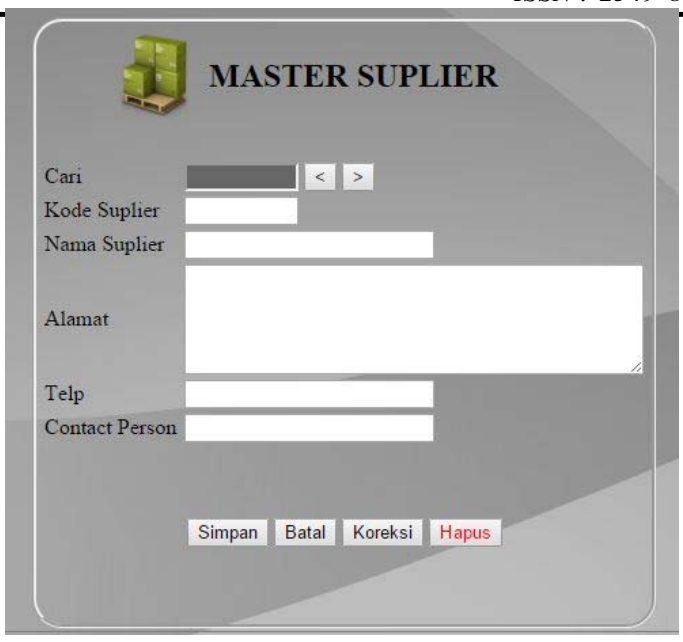

Gbr. 8 Tampilan Halaman Menu Master Suplier Sistem Informasi Penjualan

\section{F. Halaman Data Customer}

Halaman data customer merupakan untuk menampilkan data - data customer yang telah tersimpan seperti Gbr 9 .

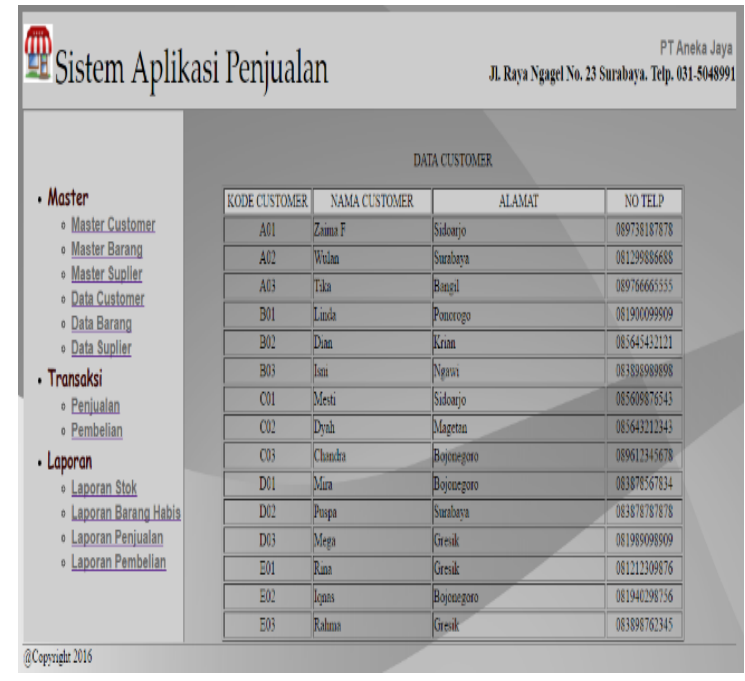

Gbr. 9 Tampilan Halaman Menu Data Customer Sistem Informasi Penjualan

\section{G. Halaman Data Barang}

Halaman tampilan data - data barang yang telah tersimpan. Apabila stok barang kurang dari 5 maka data tersebut akan berwarna biru untuk memberi tahu bahwa stok tinggal sedikit seperti Gbr 10. 


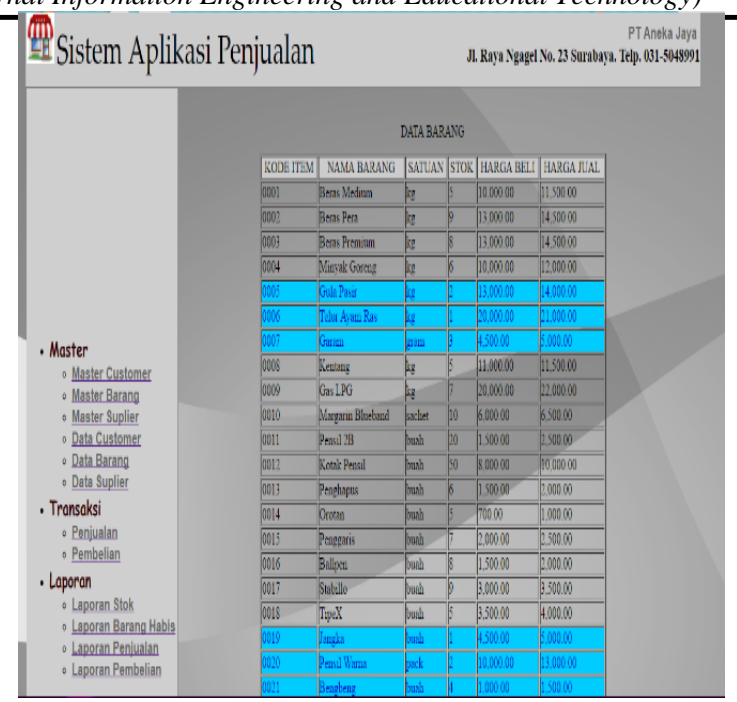

Gbr. 10 Tampilan Halaman Menu Data Barang Sistem Informasi Penjualan

\section{H. Halaman Data Suplier}

Halaman data suplier digunakan untuk menampilkan data data suplier yang telah tersimpan seperti pada Gbr 11.

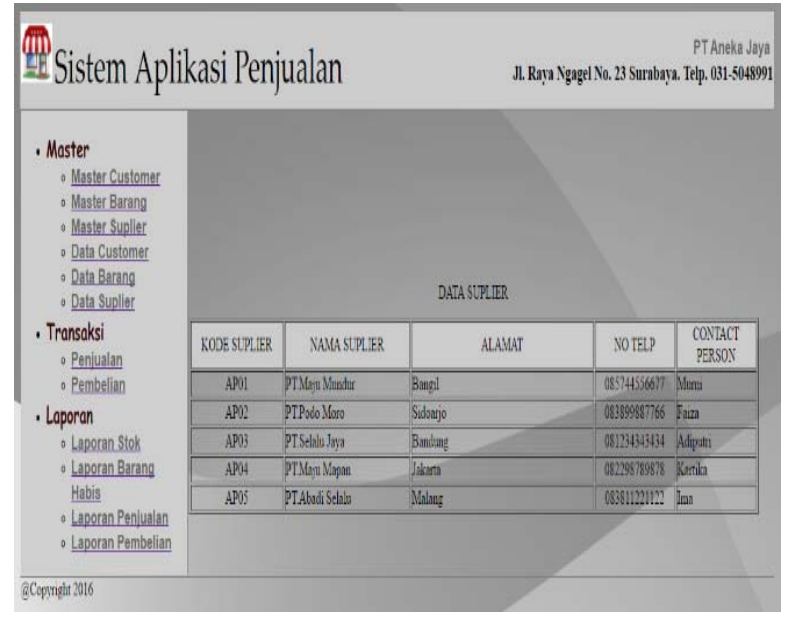

Gbr. 11 Tampilan Halaman Menu Data Suplier Sistem Informasi Penjualan

\section{Halaman Transaksi Penjualan}

Transaksi penjualan ini menyimpan data - data penjualan ke customer. Pada transaksi penjualan terdapat nomor, tanggal, customer, nama disini adalah nama customer, kasir dan shift seperti pada Gbr 12. Pada transaksi penjualan ini terdapat fungsi simpan, hapus, cetak nota dan cari. Nota yang telah dicetak merupakan hasil dari transaksi penjualan yang telah dilakukan seperti pada Gbr 13.
ISSN : 2549-869X

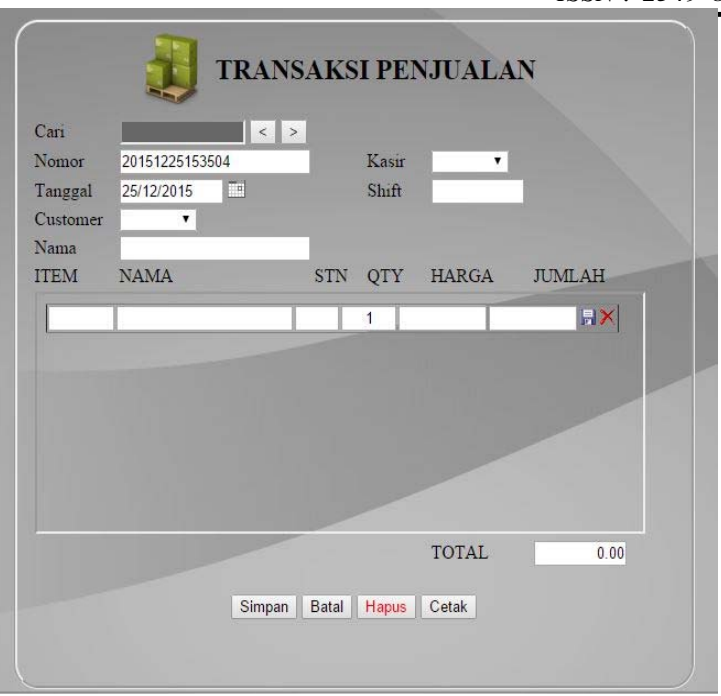

Gbr. 12 Tampilan Transaksi Penjualan Sistem Informasi Penjualan

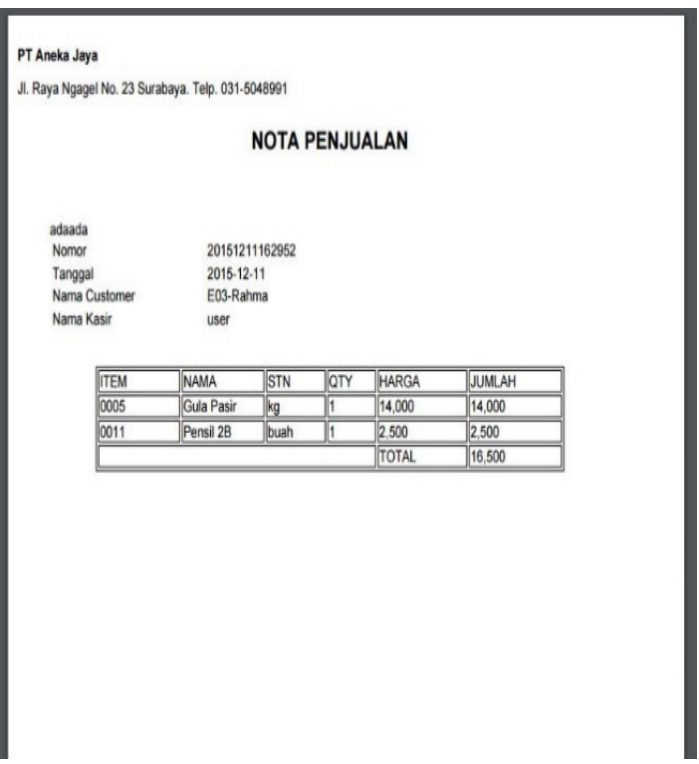

Gbr. 13 Tampilan Nota Penjualan Sistem Informasi Penjualan

\section{J. Halaman Transaksi Pembelian}

Transaksi pembelian ini menyimpan data - data pembelian dari suplier. Pada transaksi penjualan terdapat nomor, tanggal, suplier, dan nama disini adalah nama suplier. Pada transaksi penjualan ini terdapat fungsi simpan, hapus dan cari seperti pada Gbr 14. 


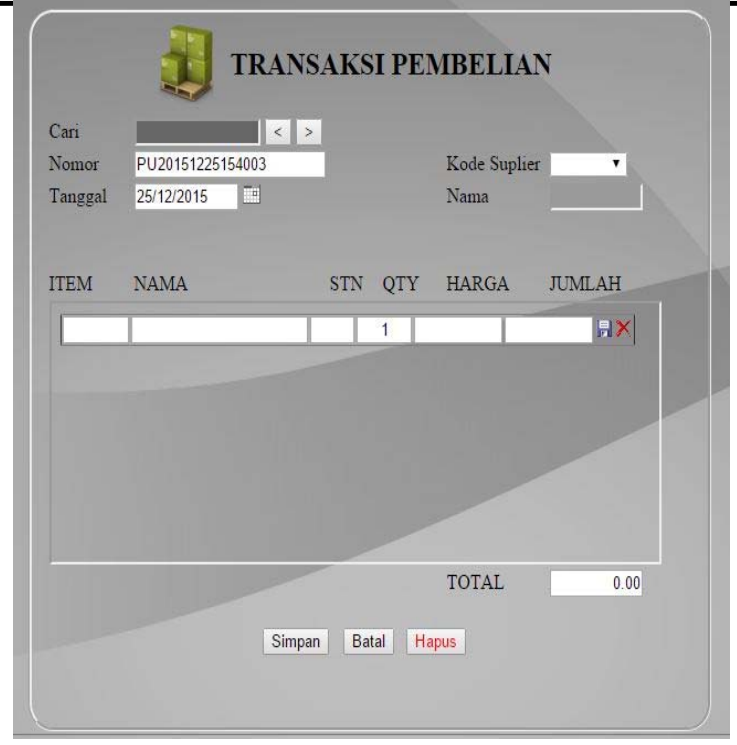

Gbr. 14 Tampilan Transaksi Pembelian Sistem Informasi Penjualan

\section{K. Halaman Laporan Stok}

Laporan stok ini diambil dari master barang, jadi barang apa saja yang telah masuk dan barang apa saja yang telah keluar serta sisa barang. Admin dapat mengisikan mulai tanggal berapa sampai tanggal berapa untuk melihat dari laporan stok yang ingin dilihat seperti pada Gbr 15. Laporan dapat dicetak dengan sesuai tanggal yang telah di inputkan pada halaman laporan stok seperti pada Gbr 16 .

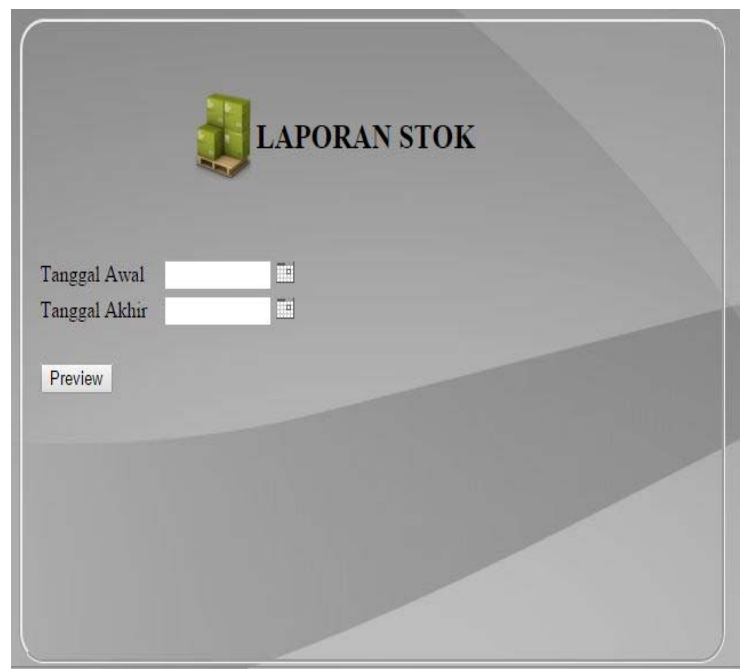

Gbr. 15 Tampilan Laporan Stok Sistem Informasi Penjualan

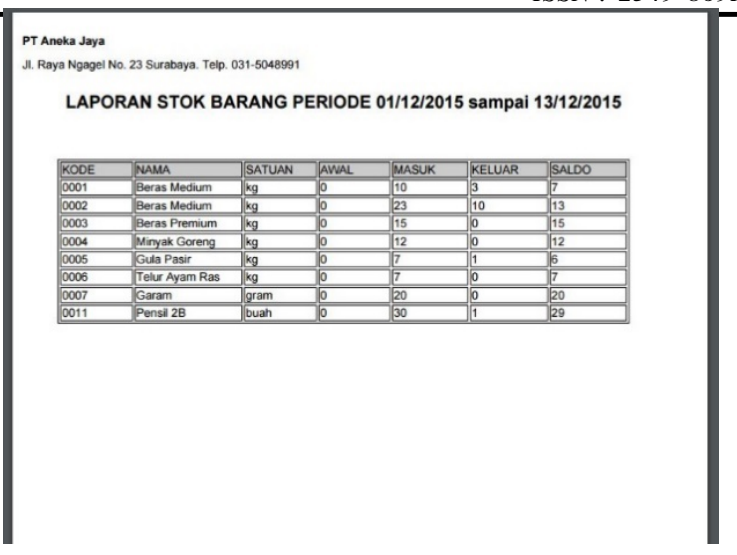

Gbr. 16 Tampilan Cetak Laporan Stok Sistem Informasi Penjualan

\section{Halaman Laporan Barang Habis}

Laporan barang habis ini diambil dari master barang. Laporan ini merupakan output dari penggunaan metode Selection Sort ascending yaitu urutan dari stok terkecil ke terbesar seperti pada Gbr 17. Laporan data barang yang habis dapat dicetak seperti pada Gbr 18.

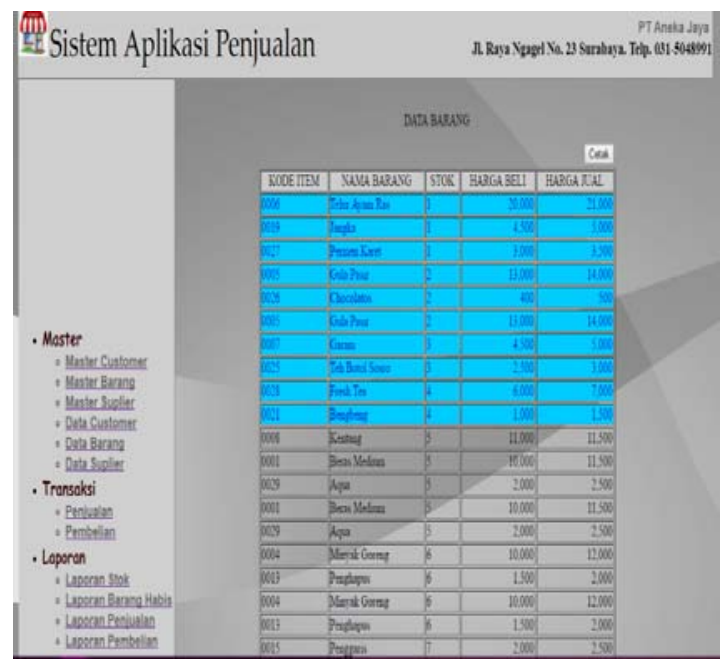

Gbr. 17 Tampilan Laporan Barang Habis Sistem Informasi Penjualan

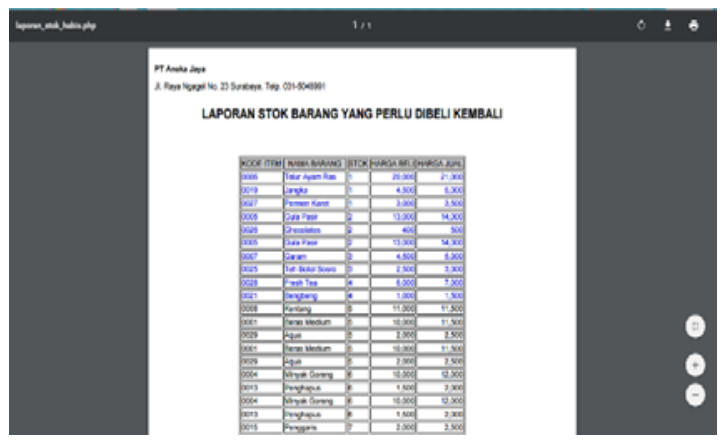

Gbr. 18 Tampilan Cetak Laporan Barang Habis Sistem Informasi Penjualan 


\section{Halaman Laporan Penjualan}

Laporan penjualan disini merupakan tempat untuk melihat total penjualan ke customer yang telah dilakukan sesuai dengan periode tanggal yang diinginkan, dengan cara memilih periode dari tanggal berapa sampai tanggal berapa kemudian klik preview seperti pada Gbr 19. Laporan dapat dicetak dengan sesuai tanggal yang telah di inputkan pada halaman laporan penjualan seperti pada Gbr 20.

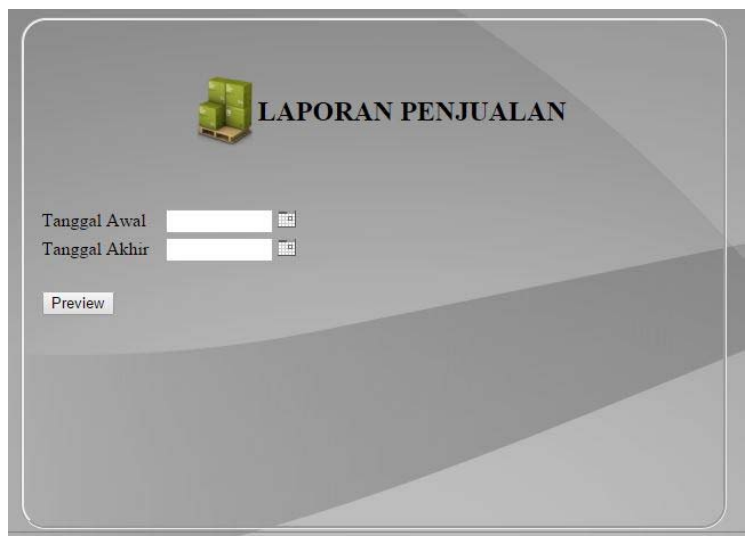

Gbr. 19 Tampilan Laporan Penjualan Sistem Informasi Penjualan

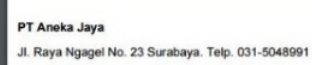

LAPORAN PENJUALAN PERIODE 01/12/2015 sampai 13/12/2015

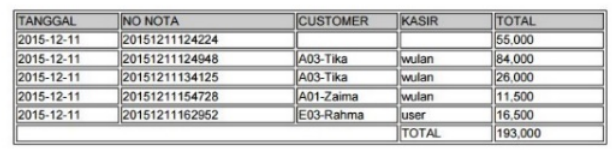

Gbr. 20 Tampilan Cetak Laporan Penjualan Sistem Informasi Penjualan

\section{N. Halaman Laporan Pembelian}

Tampilan halaman laporan pembelian. Laporan pembelian disini merupakan tempat untuk melihat total pembelian dari suplier yang telah dilakukan sesuai dengan periode tanggal yang diinginkan, dengan cara memilih periode dari tanggal berapa sampai tanggal berapa kemudian klik preview seperti pada Gbr 21. Laporan dapat dicetak dengan sesuai tanggal yang telah di inputkan pada halaman laporan pembelian seperti pada Gbr 22.

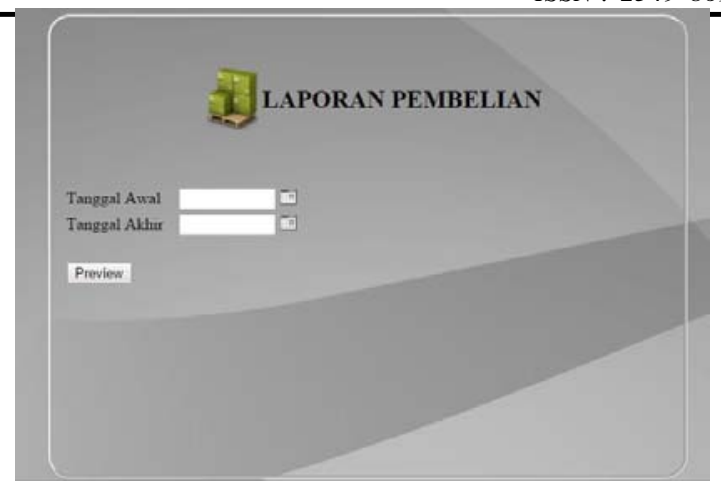

Gbr. 21 Tampilan Laporan Pembelian Sistem Informasi Penjualan

Tranes ing

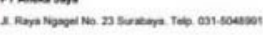

LAPORAN PENJUALAN PERIODE 01/12/2015 sampal 13/12/2015

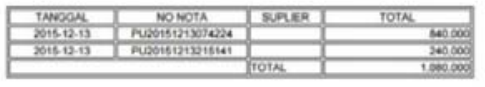

Gbr. 22 Tampilan Cetak Laporan Pembelian Sistem Informasi Penjualan

\section{KESIMPULAN}

Berdasarkan hasil penelitian yang telah diuraikan dapat diambil kesimpulan:

1) Metode Selection Sort yang digunakan yaitu ascending atau mengurutkan dari nilai terkecil ke terbesar dari stok barang. Pada sistem ini data barang dapat urut agar mempemudah user untuk mengecek barang yang perlu distok kembali.

2) Penerapan metode Selection Sort pada sistem informasi penjualan menggunakan PHP dengan database PostgreSQL. Output yang dihasilkan dari sistem informasi penjualan ini adalah laporan data barang yang telah terurut dari stok paling sedikit dan stok paling banyak.

\section{UCAPAN TERIMA KASIH}

Ucapan terimakasih kepada Tuhan Yang Maha Esa atas berkat dan rahmat yang telah diberikan kepada penulis. Terimakasih juga kepada Dr. Lilik Anifah, S.T., M.T. selaku dosen pembimbing yang telah memberikan bimbingan dan rahan kepada penulis serta teman-teman yang mendukung penulis. 
[1] P. A. Rahayuningsih, "Analisis Perbandingan Kompleksitas Algoritma Pengurutan Nilai (Sorting)," Jurnal Evolusi, vol. 4, pp. 64-75, 2016.

[2] T. F. Abidin, Struktur Data, Universitas Syah Kuala Banda Aceh: Informatika, 2008.

[3] Benordo, Masterjon dan L. N. Zulita, "IMPLEMENTASI METODE SELECTION SORT UNTUK MENENTUKAN NILAI PRESTASI KELAS 3 DAN KELAS 4 SD NEGERI 107 SELUMA," Media Infotama, vol. 11, pp. 91-100, 2015.

[4] B. K. Williams dan S. C. Sawyer, Using Information Technology, Yogyakarta: Andi, 2007.

[5] Sharingk, "Sharingk.com," 31 Maret 2013. [Online]. Available: http://sharingk.com/berita-161-membuat-database-dan-tabel-dipostgresql-.html. [Diakses 03 Januari 2016].
[6] S. N. B. Tjaru, "Kompleksitas Algoritma Pengurutan Selection Sort dan Insertion Sort," Makalah IF209 Strategi Algoritmik, 2009.

[7] A. Kadir, Pengenalan Sistem Informasi, Yogyakarta: Andi, 2014.

[8] A. Kadir, Mudah Menjadi Programmer PHP, Yogyakarta: Yescom, 2009.

[9] B. Sidik, JavaScript, Bandung: Informatika, 2011.

[10] H. Sutopo, "Selection Sort Algorithm Visualization Using Flash," The International Jurnal of Multimedia \& Its Application (IJMA), vol. 3, no. 22-35, 2011. 